\title{
SISTEM INFORMASI PRESENSI PEGAWAI PADA KANTOR KELURAHAN BUGIS SUMBAWA BESAR
}

\author{
Ahmad Yani ${ }^{1}$, Hafsah ${ }^{2}$, Linda Marlinda ${ }^{3}$ \\ STMIK Mataram ${ }^{1,2}$, \\ STMIK Nusa Mandiri ${ }^{3}$ \\ Email:m4dy45@gmail.com
}

\begin{abstract}
Abstrak
Perkembangan ilmu pengetahuan dan teknologi informasi dari waktu kewaktu mengalami perkembang dan kemajuan disegala aspek kehidupan manusia, baik dalam lembaga pendidikan, pemerintahan bahkan dalam dunia industri. Penggunaan teknologi informasi sangat penting sekali dalam menunjang dan membantu proses pengambilan keputusan yang cepat, tepat dan akurat, khuusnya dalam hal pengolahan data kehadiran pegawai yang selama ini banyak mengalami kendala. Untuk itu dibutuhkan sebuah sistem informasi dan sumber daya manusia yang memadai dan dapat membantu permaslahan presensi pegawai pada kantor kelurahan bugis sumbawa besar.
\end{abstract}

Kata kunci: sistem informasi, sumber daya manusia, presensi pegawai, pengolahan data.

\section{Latar Belakang}

Perkembangan ilmu pengetahuan dan teknologi informasi dari waktu kewaktu mengalami perkembang dan kemajuan disegala aspek kehidupan manusia, baik dalam lembaga pendidikan, pemerintahan bahkan dalam dunia industri. Penggunaan teknologi informasi sangat penting sekali dalam menunjang dan membantu proses pengambilan keputusan yang cepat, tepat dan akurat, khususnya dalam hal pengolahan data kehadiran pegawai yang selama ini banyak mengalami kendala. Untuk itu dibutuhkan sebuah sistem dan sumber daya manusia yang memadai dan dapat membantu permaslahan presensi kehadiran pegawai pada Kantor Kelurahan Bugis Sumbawa Besar.

Kantor Kelurahan Bugis Sumbawa Besar merupakan salah satu kantor pemerintahan yang memiliki pegawai yang cukup banyak sehingga membutuhkan sebuah sistem yang mampu mengelola data-data pegawai tersebut khususnya dalam hal kehadiran pegawai.

Kehadiran pegawai dalam bekerja merupakan sesuatu yang dapat menunjang dan mendukung berjalanannya pekerjaan dengan baik dan benar. Oleh karena itu kehadiran merupakan sebuah tolak ukur dalam mengontrol keefektivan pegawai dalam melaksanakan tugas dan tanggungjawabnya. Kehadiran Pegawai pada Kantor Kelurahan Bugis Sumbawa Besar sering mengalami maslah dan kendala-kendala karena apa yang dilaporkan sering tidak sesuai dengan keadaan yang sebenarnya, terutama dalam bidang presensi pegawai.

Sistem presensi pegawai yang selama ini digunakan pada Kantor Kelurahan Bugis Sumbawa Besar masih meggunakan sistem yang konvensional atau sistem manual. Dimana setiap pegawai yang baru datang akan melakukan presensi kehadiran dengan mencatat jam kehadirannya sendiri kedalam sebuah kertas/form yang sudah disediakan pada bagian sekretariat, sehingga banyak diantara pegawai-pegawai yang tadinya datang terlambat atau tidak sesuai dengan jam kerja, tetap bisa mengisi jam kerja mereka tepat dengan waktunya. Sehingga laporan yang dihasilkan untuk mengontrol jam kerja pegawai menjadi tidak efektiv dan valid karena semua pegawai dapat merubah dan memanipulasi data kehadiran tersebut.

Dengan memperhatikan permasalahan yang dihadapi oleh Kantor Kelurahan Bugis Sumbawa Besar, maka dibutuhkan sebuah sistem informasi yang dapat membantu Kantor Kelurahan Bugis Sumbawa Besar dalam mengelola dan mengontrol kehadiran pegawai yakni Sistem Informasi Presensi Pegawai.

Adapun batasan-batasan masalah dalam pembuatan sistem informasi ini adalah sebagai berikut :

a. Sistem informasi ini dibangun menggunakan pemrogram delphi 7.0 dan Ms. Acces sebagai databasenya.

b. Sistem ini hanya membahas data pegawai yang ada pada Kantor Kelurahan Bugis Sumbawa Besar.

c. Sistem informasi ini juga dibangun untuk menggatikan sistem yang lama (Sistem Manual) menjadi sistem yang terkomputerisasi.

\section{Landasan Teori}

a. Pengertian Sistem 
Sistem merupakan bagian-bagian yang saling berkaitan dan beroperasi bersama untuk mencapai beberapa sasaran atau maksud. (AlBahra Bin Ladjamudin , 2005, hal:3) .

Sedangkan menurut Jogiyanto (2008:34) sistem dapat didefenisikan dengan pendekatan prosedur dan dengan komponen. Dengan pendekatan prosedur, sistem dapat didefenisikan sebagai kumpulan dari prosedur-prosedur yag mempunyai tujuan tertentu. Sedangkan dengan pendekatan komponen, sistem dapat didefinisikan sebagai kumpulan dari komponen yang saling berhubungan satu dengan yang lainnya membentuk satu kesatuan untuk mencapai tujuan tertentu.

Jadi pengertian sistem adalah sekumpulan elemen yang saling terkait dan terpadu yang dimaksudkan untuk mencapai suatu tujuan tertentu.

Sistem itu sendiri memiliki karakteristik atau beberapa sifat tertentu, yaitu mempunyai komponen (components), batas sistem (boundary), lingkungan luar sistem (environments), penghubung (interfce), masukan (input), keluaran (output), pengolah (process), dan sasaran suatu tujuan (goal).

b. Pengetian Informai

Berbicara mengenai informasi tidak akan lepas dengan yang namanya data dan teknologi. Informasi merupakan hasil pengolahan data dari satu atau berbagai sumber, yang kemudian diolah, sehingga memberi nilai, arti, dan manfaat. Proses pengelolaan ini memerlukan ternologi, berbicara mengenai teknologi memang tidak harus selalu berkaitan dengan komputer, namun komputer sendiri merupakan salah satu bentuk teknologi. Dengan kata lain, alat tulis dan mesin ketik pun dapat dimasukkan sebagai salah satu teknologi yang digunakan selain komputer dan jaringan komputer.

Pada proses pengelolahan data, untuk dapat menghasilkan informasi, juga dilakukan proses verifikasi secara akurat, spesifik, dan tepat waktu. Hal ini penting agar informasi dapat memberikan nilai dan pemahaman kepada pengguna. Pengguna dalam hal ini mencangkup pembaca, pendengar, penonton, bergantung pada bagaimana cara pengguna tersebut menikmati sajian informasi dan melalui media apa informasi tersebut disajikan. (I Putu Agus Eka Pratama, $2014: 8$ )

c. Pengetian Sistem Informasi

Sistem Informasi adalah suatu sistem didalam suatu organisasi yang mempertemukan kebutuhan pengolahan transaksi harian yang mendukung fungsi operasi organisasi yang bersifat manajerial dengan kegiatan strategi dari suatu organisasi untuk dapat menyediakan laporan-laporan yang diperlukan oleh pihak luar tertentu. (Tata Sutabri, 2012 : 38).

Menurut Tata Sutabri dalam buku Analisis Sistem Informasi (2012:39). Sistem informasi terdiri dari 6 (enam) komponen yaitu:

1) Blok Masukan (Input Block) Yang dimaksud dengan input disini termasuk metode dan media untuk menangkap data yang akan dimasukkan.

2) Blok Model (Model Block)

Blok ini terdiri dari kombinasi prosedur, logika, dan model matematik yang akan memanipulasi data input dan data yang tersimpan di basis data dengan cara yang sudah tertentu untuk menghasilkan keluaran yang diinginkan.

3) Blok Keluaran (Output Block)

Keluaran informasi yang berkualitas dan dokumentasi yang berguna untuk semua tingkatan manajemen serta semua pemakai sistem.

4) Blok Teknologi (Technology Block) Teknologi digunakan untuk menerima input, menjalankan model, menyimpan, mengakses data dan menghasilkan keluaran.

5) Blok Basis Data (Database Block)

Kumpulan data yang saling berkaitan dan berhubungan satu dengan lainnya.

6) Blok Kendali (Control Block)

Beberapa pengendalian perlu dirancang dan diterapkan untuk menyakinkan bahwa hal-hal yang dapat merusak sistem dicegah dan bila terlanjur terjadi maka kesalahan-kesalahan dapat dengan cepat diatasi.

\section{Metodologi Penelitian}

Pada rekayasa perangkat lunak, banyak model yang telah dikembangkan untuk membantu proses pengembangan perangkat lunak. Modelmodel ini pada umumnya mengacu pada model proses pengembangan sistem yang disebut System Development Life Cycle (SDLC). Untuk menggunakan SDLC maka dibutuhkan sumber data awal dari pengguna yang dijadikan acuan dalam perencanaan, analisa, perancangan dan implementasi. Penggunaan acuan ini dimaksudkan agar sistem yang dibangun bisa menjembatani kebutuhan penelitian dari permasalahan yang dihadapinya. Ada pun langkah-langkah yang di tempuh dalam penelitian ini adalah : 
a. Perencanaan

Fase perencanaan adalah sebuah proses dasar untuk memahami mengapa sebuah sistem harus dibangun. Pada fase ini diperlukan analisa kelayakan dengan mencari data atau melakukan proses information gathering kepada pengguna.

b. Analisa

Fase analisa adalah sebuah proses investigasi terhadap sistem yang sedang berjalan dengan tujuan untuk mendapatkan jawaban mengenai pengguna sistem, cara kerja sistem dan waktu penggunaan sistem. Dari proses analisa ini akan didapatkan cara untuk membangun sistem baru.

c. Rancangan

Fase perancangan merupakan proses penentuan cara kerja sistem dalam hal architechture design, interface design, database dan spesifikasi file, dan program design. Hasil dari proses perancangan ini akan didapatkan spesifikasi sistem.

d. Implementasi

Fase implementasi adalah proses pembangunan dan pengujian sistem, instalasi sistem, dan rencana dukungan sistem.

\section{Implementasi Sistem dan Hasil}

Pada implementasi sistem dan hasil akan diuraikan tentang sistem yang sedang berjalan, sistem baru/alternativ, diagram alur, ERD, struktur database, struktur program dan implementasi hasil dari program presensi pegawai yang telah dibuat.

a. Sistem Berjalan

Untuk mengetahui sistem yang sedang diterapkan atau berjalan, maka dilakukan observasi secara lansung pada pada kontor keluruhan bugis sumbawa besar. Adapun hasil dari analisis sistem yang berjalan dapat dilihat pada gambar 1 berikut:

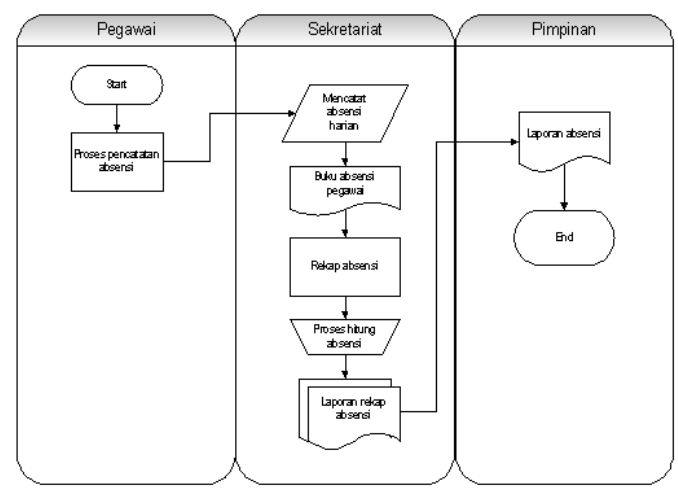

Gambar 1 Sistem Berjlan
Pada Sistem berjalan data absensi pegawai bersumber dari sebuah berkas/form yang telah dibuat dan diisi setiap harinya oleh para pegawai kelurahan. Dalam pengisian absensi secara manual penulis mendapati terdapat bebrapa kelemahan di absensi. Karena pegawai dapat mengisi absensi jam berapa saja tanpa ada keterangan terlambat, sehingga akan dapat pegawai tersebut mengisi absensi dengan catatan masuk tepat waktu, walaupun pegawai tersebut datang pada jam yang tidak sesuai dengan aturan (terlambat). Setelah pegawai mengisi absensi tiap harinya, maka absensi yag diisi tersebut akan di simpan pada bagian kepegawaian atau sekretariatan pada kelurahan untuk di buat laporan absensi bulanan. Karena kurangnya pengawasan terhadap pengisian absensi maka jarang sekali pegawai kelurahan yang terlambat apalagi tidak masuk. Sehingga laporan absensi menjadi tidak valid ketika dibuat laporan ke pimpinan. Maka dari hasil obevasi inilah maka dibutuhkan sebuah sistem yang dapat membantu mengatasi permalahan presensi tersebut dengan cara membuat sistem baru atau sistem alternativ.

b. Sistem Baru/ Alternativ

Sistem baru ini dirancang untuk memberikan kemudahan dan membantu kepala kantor dalam meningkatkan etos kerja dan kedisiplinan serta kejujuran pegawai dalam bekerja. Adapun desain baru/alternativ dari program yang dibuat seperti terlihat pada gambar 2 berikut:

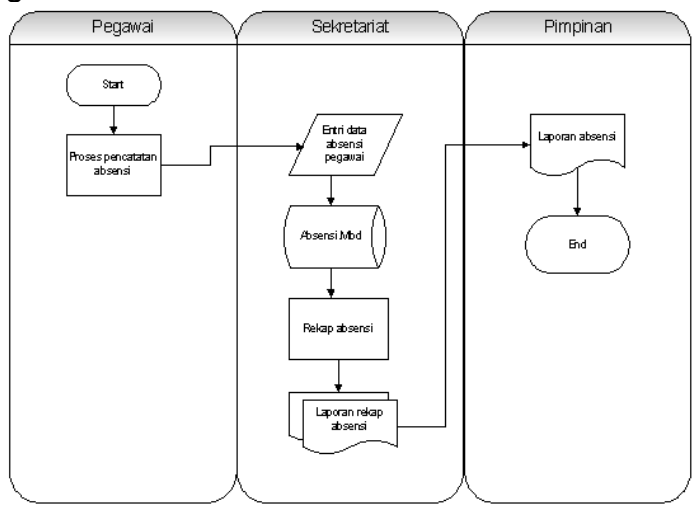

Gambar 2. Sistem Baru/ Alternativ

Pada desain sistem yang baru perubahan sistem dari yang sifatnya manual (mencatat dalam form/berkas) di arahkan ke sebuah sistem yang terintegerasi ke dalam sebuah database (Absensi.Mdb). Desain baru akan di diterapkan sistem yang lebih baik dari yang sebelumnya, karena di desain sebelumnya para pegawai dapat memanipulasi data (jam) masuk kerja tanpa ada keterangan terlambat 
maka dengan sistem informasi presensi ini hal tersebut tidak akan dapat dilakukan oleh pegawai. Karena untuk mengisi absensi para pegawai terlebih dahulu mencari NIP pegawai tersebut. Jika status pegawai tersebut masih aktif maka proses pengabsensian dapat dilakukan. Tapi jika status pegawai tersebut tidak aktif karena mutasi dan lain-lainya maka absensi tidak dapat dilaksanakan. Setelah pegawai tersebut menemukan NIPnya pegawai tersebut melakukan proses absensi dengan memilih menu yang ada. Hasil seluruh absensi para pegawai akan tersimpan dalam sebuah database Absensi.Mdb. yang mana data yang terdapat dalam Absensi.Mdb akan digunakan untuk membuat pelaporan kehadiran para pegawai yang akan disampaikan ke pimpinan.

c. DFD

Data Flow Diagram (DFD) adalah gambaran sistem secara logika. Gambaran ini tidak tergantung pada perangkat keras, lunak, srtuktur data atau organisasi. Pada tahap analisa, penanganan notasi simbol lingkaran dan anak panah mewakili/menggambarkan arus data dalam perancangan sistem sangat membantu sekali di dalam komunikasi dengan pemakai sistem menggunakan notasinotasi ini untuk menggambarkan arus dari data sistem.

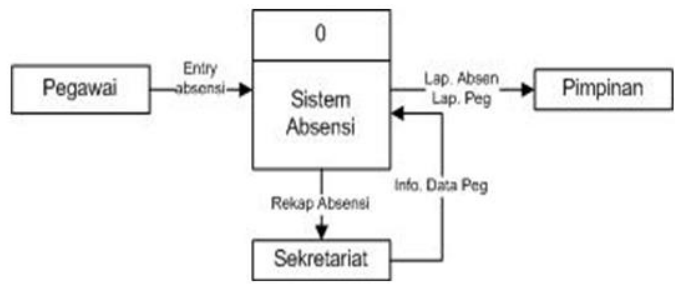

Gambar 3 DFD

Gambar 3 ini menunjukan diagram alur yang terjadi dalam sistem, dimana ada 3 entitas yang terlibat lansung dengan sistem yakni pegawai, sekretariat dan pimpinan.

Pegawai hanya dapat melakukan absensi tanpa bisa merubah apapun didalam sistem. Sekretariat adalah pihak yang mengoprasikan sistem dan membuat laporan kepada pimpinan sedangkan pimpinan adalah orang yang menerima laporan.

d. ERD

ERD (Entity Relationship Diagram) yang merupakan model data yang berorientasi objek (ER-Model), yang tentunya nanti akan menghasilkan suatu basis data yang sama baik menggunakan normalisasi ataupun dengan menggunakan ERD. Untuk merancang sebuah basis data dengan metode ERD dapat dilakukan dengan lima (5) langkah yaitu :

1) Mengidentifikasikan dan menetapkan seluruh himpunan entity yang akan terlibat.

2) Menentukan atribut-atribut key dari masingmasing himpunan entitas.

3) Mengidentifikasi dan menetapkan seluruh himpunan relasi diantara himpunan entitas yang ada beserta foreign keynya.

4) Menetukan derajat kardinalitas rasio relasi untuk setiap himpunan selasi.

5) Melengkapi himpunan relasi dengan atributatribut yang bukan kunci.

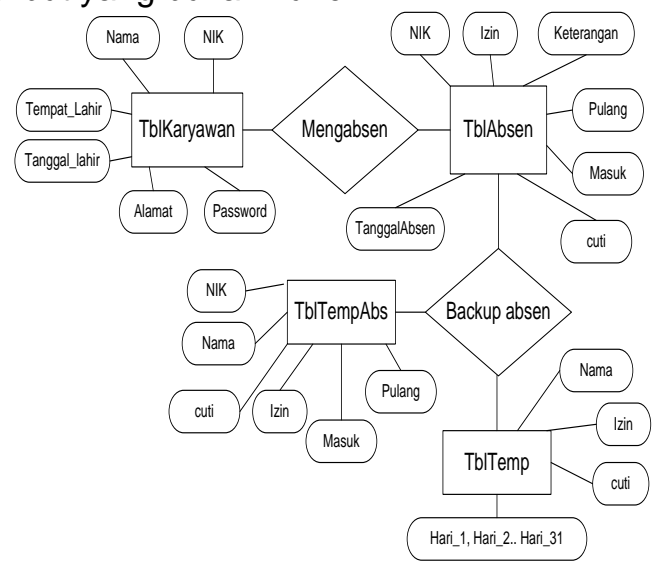

Gambar 4. ERD

Gambar 4 menunjukan susunan data yang disimpan dari sistem abstrak dengan tujuan untuk menunjukkan obyek data dan relationship yang ada pada suatu obyek atau tabel.

e. Struktur Database

Adapun struktur databae dalam pembuatan aplikasi presensi pegawai ini terdiri dari 4 tabel yaitu tabel Pegawai (Tblkaryawan), tabel Absensi (Tblabsen), Table Temp (TblTemp), dan Tabel TempAbs (TblTempAbs).

1) Tabel karyawan (Tbl_karyawan).

Tabel 1 Tblkaryawan

\begin{tabular}{|l|l|c|l|c|}
\hline No & Nama field & Type & Size & Key \\
\hline 1 & NIK & Text & 15 & ${ }^{*}$ \\
\hline 2 & Nama & Text & 30 & \\
\hline 3 & Alamat & Text & 40 & \\
\hline 4 & Tanggal_lahir & Date & - & \\
\hline 5 & Tempat_Lahir & Text & 15 & \\
\hline 6 & Jenis_Kelamin & Text & 10 & \\
\hline 7 & Status & Yes/No & - & \\
\hline 8 & Password & Text & 5 & \\
\hline 9 & No_Telephon & N & 12 & \\
\hline
\end{tabular}


2) Tabel Absen (Tbl_Absen).

Tabel 2 Tblabsen

\begin{tabular}{|l|l|c|c|c|}
\hline No & Nama field & Type & Size & Key \\
\hline 1 & NIK & Text & 15 & $*$ \\
\hline 2 & $\begin{array}{l}\text { Tanggalabs } \\
\text { en }\end{array}$ & Date/time & - & $* \star$ \\
\hline 3 & Masuk & Date/time & - & \\
\hline 4 & Pulang & Date/time & - & \\
\hline 5 & Izin & Date/time & - & \\
\hline 6 & Cuti & Date/time & - & \\
\hline 7 & Keterangan & Text & 30 & \\
\hline
\end{tabular}

3) Tabel TempAbs (Tbl_TempAbs).

Tabel 3 Tbl_TempAbs

\begin{tabular}{|l|l|l|l|l|}
\hline No & Nama field & Type & Size & Key \\
\hline 1 & NIK & Text & 15 & \\
\hline 2 & $\begin{array}{l}\text { Nama_Karya } \\
\text { wan }\end{array}$ & Text & 30 & \\
\hline 3 & Masuk & Date/time & - & \\
\hline 4 & Pulang & Date/time & - & \\
\hline 5 & Izin & Date/time & - & \\
\hline 6 & Cuti & Date/time & - & \\
\hline 7 & Keterangan & Text & 30 & \\
\hline 8 & Flag & Text & 2 & \\
\hline
\end{tabular}

4) Tabel Temp (Tbl_Temp).

Tabel 3 Tbl_Temp

\begin{tabular}{|c|l|c|c|c|}
\hline No & Nama field & Type & Size & Key \\
\hline 1 & Nama_karyawan & Text & 15 & \\
\hline 2 & Izin & Date/time & - & \\
\hline 3 & Cuti & Date/time & - & \\
\hline 4 & Hari_1 & Text & 2 & \\
\hline 5 & $\ldots$ Hari_31 & Text & 2 & \\
\hline
\end{tabular}

f. Struktur Program

Struktur atau rancangan program yang dibuat bertujuan agar user dapat mengerti hirarki dari aplikasi preseni yang akan dibangun. Adapun gambar dari struktur program dapat dilihat pada gambar 5 berikut:

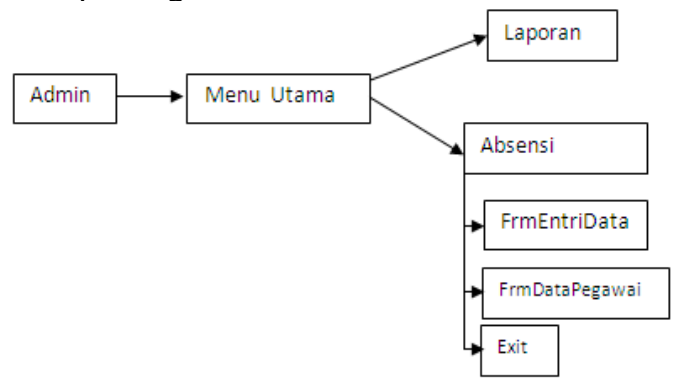

Gambar 5 Struktur Program

Pada gambar 5 tersebut di gambarkan proses admin dalam mengelola program atau aplikasi presensi yang dibuat, sehingga kevalid data absensi terhadap pegawai tetap bisa terjaga dengan baik, karena dalam aplikasi ini pegawai hanya bisa melakukan absensi saja tanpa bisa merubah apapun yang ada didalam program.

g. Implementasi Hasil

Pada bagian ini akan dijelaskan tentang hasil dari program yang sudah dibuat dan dimplementasikan pada kantor kelurahan bugis sumbawa besar. Adapun implementasi hasil dari program presensi ini adalah sebagai berikut:

\section{1) Form Login}

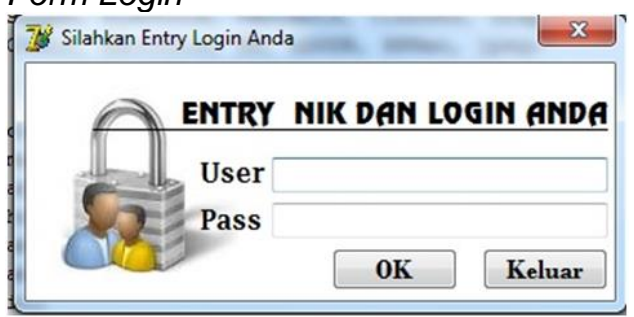

Gambar 6 Form Login

Form Login ini digunakan oleh admin atau operator dalam hal ini sekretariat kantor kelurhan bugis sumbawa besar untuk masuk kemenu utama program.

2) Form Menu Utama

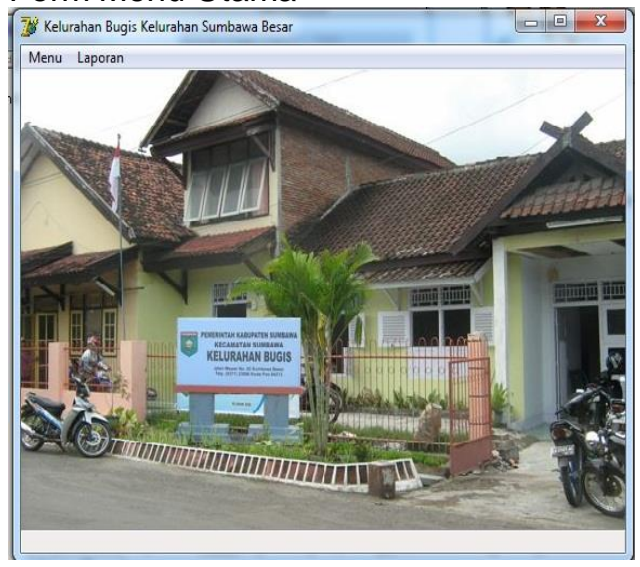

Gambar 7. Form Menu Utama

Form menu utama ini akan tampil setelah operator atau sekretariat kantor bugis sumbawa besar melakukan login. Dimana pada form menu utama ini operator akan melakukan pengelolaan terhadap program absensi dalam hal, penginputan data pegawai dan pembuatan laporan absensi pegawai kepada pimpinan pada tiap awal bulan.

3) Form Input Data Pegawai 


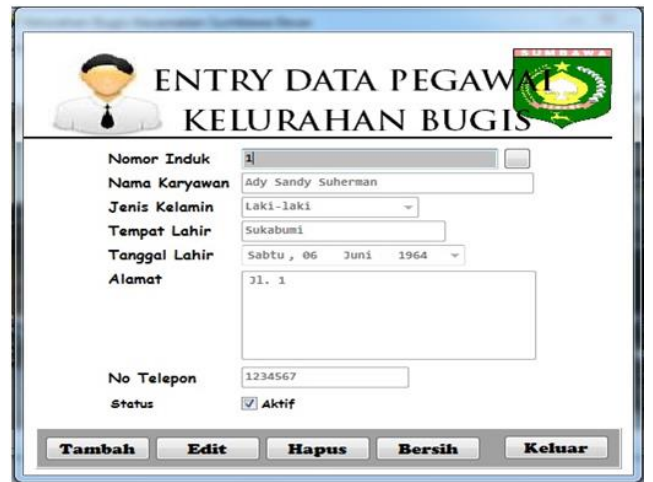

Gambar 8 Form Input Data Pegawai Form ini digunakan oleh operator kantor kelurahan bugis untuk mendaftarkan atau memasukan semua pegawai yang ada pada kantor kelurahan bugis sumbawa besar, sehingga semua pegawai terdata/terdaftar dalam program presensi dan dapat melakukan presensi kehadiran setiap harinya.

4) Form Login Absensi Pegawai

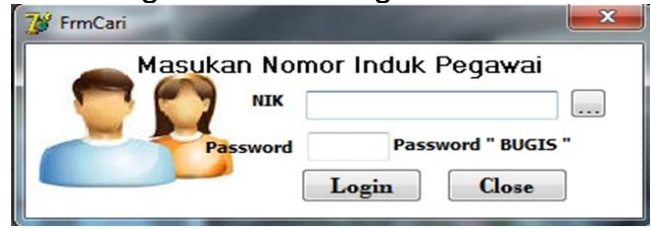

Gambar 9 Form Login Absensi Pegawai Form absensi pegawai ini digunakan oleh setiap pegawai pada kantor keluran bugis sumbawa besar untuk melakukan presensi kehadiran sesuai dengan NIK dan Password yang telah didaftarkan pada waktu penginputan data pegawai. Setelah pegawai memasukan NIK dan Password, selanjutnya pegawai menekan tombol login untuk masuk ke menu abensi seperti terlihat pada gambar 10 berikut.

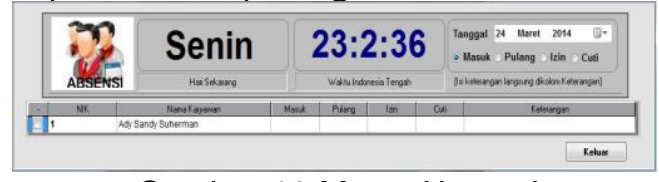

\section{Gambar 10 Menu Absensi}

Pada gambar 10 ini pegawai akan melakukan absensi dengan cara memilih salah satu option pilihan yang terdapat pada menu absensi seperti masuk, pulang, ijin atau cuti dan mengisi kolom keterangan sesuai dengan alasan ijin atau cuti pegawai untuk jangka waktu beberapa hari.

5) Form Laporan Absensi

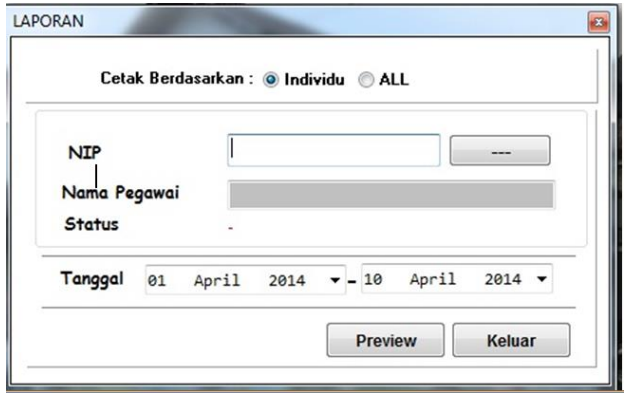

Gambar 11 Form Laporan Absensi

Form laporan absensi ini dikelola oleh operator atau sekretariat kantor kelurahan bugis sumbawa besar untuk melakukan rekapitulasi atas kehadiran pegawai selama satu bulan penuh. Pada menu laporan ini terdapat dua option atau dua pilihan dalam pembuatan laporan absensi pegawai yakni laporan per individu atau laporan absensi secara keselurahan pegawai yang terdapat dan terdata sebagai pegawai pada kantor kelurahan bugis sumbawa besar. Adapun bentuk laporan absensi pegawai pada kantor kelurahan bugis sumbawa besar baik secara individu dan keseluruhan dapat dilihat pada gambar 12 dan gambar 13 berikut:

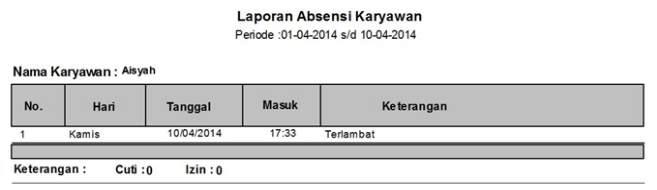

Gambar 12 Laporan Per Individu

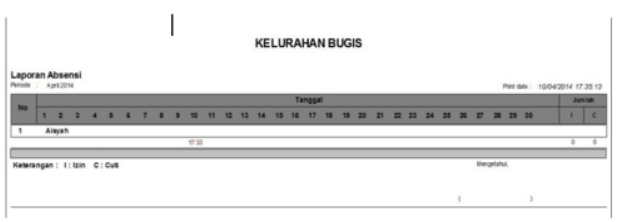

Gambar 13 Laporan keseluruhan

\section{Penutup}

Sistem informasi Presensi Pegawai pada Kantor Kelurahan Bugis Sumbawa Besar ini yang dibangun menggunakan Pemrograman Delphi 7.0 dan Database menggunakan MS. Access. Sistem Informasi Presensi Pegawai pada Kantor Kelurahan Bugis dibangun untuk mengganti sistem yang selama ini masih menggunkan sistem manual menjadi sistem yang terkomputerisasi. Dengan sistem manual semua pegawai bisa merubah dan memanipulasi kehadiran baik dalam hal masuk kerja atau pun pada jam pulang kerja, sehingga dengan adanya sistem baru ini dapat 
memberikan kevalidan dalam memberikan laporan terhadap kehadiran pegawai pada Kantor Kelurahan Bugis Sumbawa Besar.

\section{Daftar Pustaka}

Al-Bahara Bin Ladjamuddin. (2005). Analisis dan Desain Sistem Informasi. Yogyakarta: Graha IImu.

Jogiyanto. (2008). Metodelogi Penelitian Sistem Informasi, Yogyakarta: Andi Offset

Pratama, Eka : 2014.Sistem Informasi dan Implementasinya. Bandung : Informatika

Sutabri, T. 2012. Analisis sistem informasi. Yogyakarta : CV Andi Offset. 